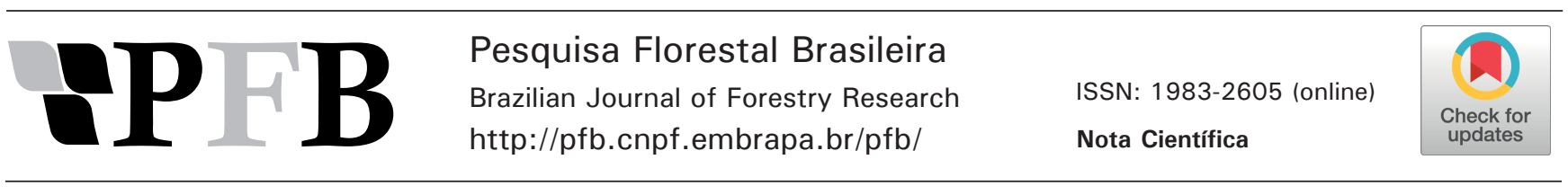

\title{
Interceptação de Sinoxylon unidentatum (Coleoptera: Bostrichidae) no Rio de Janeiro, Brasil
}

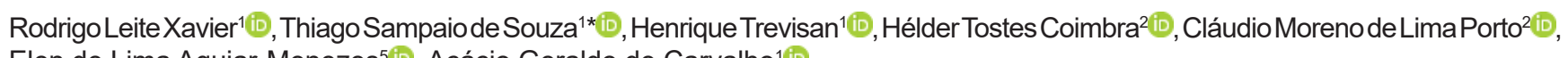
Elen de Lima Aguiar-Menezes ${ }^{5}$ (D) Acácio Geraldo de Carvalho ${ }^{(i D}$

${ }^{1}$ Universidade Federal Rural do Rio de Janeiro, Rodovia BR 465, Km 7 S/N, CEP 23897-000, Seropédica, RJ, Brasil

${ }^{2}$ Superintendência Federal de Agricultura, Pecuária e Abastecimento do Rio de Janeiro, Av. Rodrigues Alves, 129, Centro, CEP 20081-250, Rio de Janeiro, RJ, Brasil

"Autor correspondente:

thiagosampaio.agro@gmail.com

Termos para indexação:

Brocas da madeira

Praga quarentenária A2

Brometo de metila

Index terms:

Wood borers

Quarantine pest A2

Methyl bromide

Histórico do artigo:

Recebido em 25/10/17

Aprovado em 27/03/18

Publicado em 09/07/18

doi: 10.4336/2018.pfb.e201701522

\begin{abstract}
Resumo - A ocorrência da praga quarentenária (A2), Sinoxylon unidentatum Fabricius (Coleoptera: Bostrichidae) foi confirmada e interceptada no Porto do Rio de Janeiro, em paletes oriundos da Indonésia. Constatou-se que o brometo de metila não foi suficiente para inibir a ação dos insetos nos paletes. Sugere-se, como medida de monitoramento, a instalação de armadilhas etanólicas nos locais de armazenamento e trânsito de madeiras ou material lenhoso.
\end{abstract}

\section{Interception of Sinoxylon unidentatum (Coleoptera: Bostrichidae) in Rio de Janeiro State, Brazil}

\begin{abstract}
The occurrence of quarantine pest (A2), Sinoxylon unidentatum Fabricius (Coleoptera: Bostrichidae) was confirmed and intercepted in Rio de Janeiro port on pallets originated from Indonesia. It was found that methyl bromide was not sufficient to inhibit the action of the insects on the pallets. It is suggested as monitoring measure, the installation of ethanolic traps storage sites and transit of wood.
\end{abstract}

Os insetos da família Bostrichidae (Coleoptera) são pequenos e possuem o hábito de construir galerias no interior da madeira e de toras recém-cortadas (Furniss \& Carolin, 1977; Lunz et al., 2010).

Paletes de madeira são comumente utilizados em atividades comerciais internacionais, contribuindo com intenso trânsito de insetos em distintas regiões geográficas (Peres Filho et al., 2006).

Sinoxylon unidentatum Fabricius (Coleoptera: Bostrichidae) foi detectado no Brasil pela primeira vez em 2001 no município de Várzea Grande, MT e em
2004 em Cuiabá, MT, causando danos em teca (Tectona grandis L. f.) (Peres Filho et al., 2006).

Atualmente, esta praga faz-se presente somente no Mato Grosso (Peres Filho et al., 2006; Lunz et al., 2010; Brasil, 2013), porém, danificando outras espécies arbóreas, como: bálsamo (Myroxylon peruiferum L. f.), caju (Anacardium occidentale L.), flamboyant [Delonix regia (Bojer ex Hook) Raf.], manga (Mangifera indica L.), mogno (Switenia macrophyla King), seringueira [Hevea brasiliensis (Willd. ex A. Juss.) Müll. Arg.], além da teca (Brasil, 2013). 
Este trabalho registra a presença de $S$. unidentatum, praga quarentenária presente (A2) (Brasil, 2008), em paletes no Rio de Janeiro.

Os paletes de madeira, os quais foram produzidos com madeiras provindas de espécies exóticas pertencentes ao grupo botânico Angiospermae, eram originários da Indonésia e estavam sendo usados para apoio de carga de produtos cosméticos. Embora tratados com brometo de metila no país de origem, apresentaram a presença do inseto. O gênero Sinoxylon está presente na lista de pragas quarentenárias para o Brasil, podendo ser introduzido através de toras de madeira, madeira serrada, incluindo as madeiras de embalagem e suporte de mercadorias (Penteado et al., 2010).

O tratamento químico adotado nestes paletes atende ao estabelecido na Convenção Internacional para a Proteção dos Vegetais (CIPV), em conformidade com as Normas Internacionais de Medidas Fitossanitárias (NIMF) n ${ }^{\circ} 15$ (Brasil, 2009). Para se evitar dispersões de pragas A1 e A2, devem-se ser adotadas as normatizações [IN no 36/2006 (Brasil, 2006), IN no 32/2015 (Brasil, 2015a), no 28/2016 (Brasil, 2016a) e no 33/2016 (Brasil, 2016b)] e procedimentos padrões de inspeção física de fiscais do Ministério da Agricultura, Pecuária e Abastecimento (MAPA).

Em atendimento aos requisitos de fiscalização do MAPA, no dia 16 de novembro de 2016 foi realizada inspeção, por auditores fiscais federais do porto do Rio de Janeiro (22 $\left.52^{\prime} 33.0^{\prime \prime} \mathrm{S}, 43^{\circ} 12^{\prime} 36.8^{\prime \prime} \mathrm{W}\right)$ em paletes de madeira provindos da Indonésia. Após a verificação da presença de serragem com consistência de "talco" sendo expelida da madeira, procedeu-se à amostragem do material. As amostras foram cortadas com serra, colocadas em saco plástico transparente, sendo a abertura do saco vedada com fita adesiva. A amostra do material identificado foi posteriormente inspecionada para localização dos insetos nas galerias (Figura 1). Espécimes presentes nos paletes foram coletados, depositados em recipiente de vidro transparente contendo $50 \mathrm{~mL}$ de álcool 70\%, identificado (amostra: 18.968, protocolo: 82.863), lacrado e encaminhado ao laboratório credenciado na Rede Nacional de Laboratórios Agropecuários do Sistema Unificado de Atenção à Sanidade Agropecuária, em Porto Alegre, RS, para identificação. Em 23 de novembro de 2016 o resultado da análise foi positivo para a praga quarentenária presente (A2), S. unidentatum.
De acordo com a IN n 32/2015, ao verificar-se uma situação como essa, a mercadoria e os suportes de madeira devem passar por tratamento fitossanitário com fins quarentenários e serem restituídos ao país de origem (Brasil, 2015a), procedimento este que foi realizado com o material.

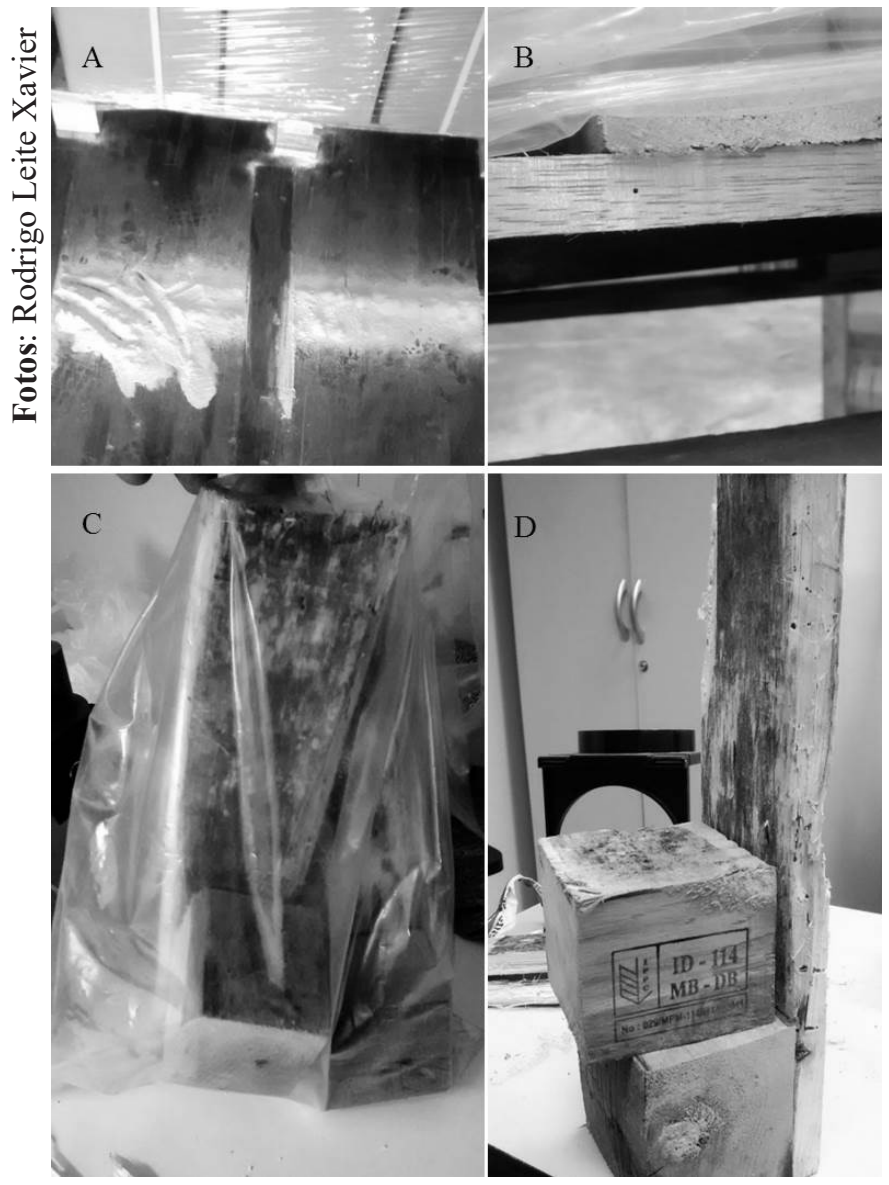

Figura 1. Verificação de resíduos de madeira no interior do contêiner (A), orifício causado por Sinoxylon unidentatum (Coleoptera: Bostrichidae) em palete (B), amostra coletada do palete infestado (C) e amostra do palete em fase de inspeção para exposição dos indivíduos nas galerias (D).

Os tratamentos autorizados, de modo geral, se mostram eficientes para o controle de pragas, pois têm poder curativo, embora algumas formulações possuam ação residual pouco significativa, como no caso do brometo de metila (Agência de Defesa Agropecuária do Paraná, 2017). O tempo médio de liberação dos contêineres dos pátios do porto do Rio de Janeiro, RJ é de 12 dias e do porto de Santos, SP de 10 dias (Cai tempo..., 2017; Fariello \& Ordoñez, 2017). Na 
Indonésia, o tempo máximo de liberação dos contêineres dos portos varia de um a dois meses, dependendo do porto (Brasil, 2015b). Assim, mesmo com o tratamento curativo realizado, o tempo de espera para liberação dos contêineres nos portos pode propiciar uma reinfestação de insetos-praga em paletes ou, até mesmo, uma menor eficiência do tratamento químico, com mortalidade dos insetos presentes nos paletes não atingindo $100 \%$. Outras interceptações de $S$. unidentatum em paletes oriundos da Índia já foram realizadas no porto de Vitória, ES (Peres Filho et al., 2006).

O transporte de mercadorias favorece o trânsito e a dispersão de diversas espécies de insetos-praga. O uso de armadilhas etanólicas para captura e monitoramento de insetos broqueadores é realizado de forma frequente em estudos de entomologia florestal (Flechtmann \& Gaspareto, 1997; Ferraz et al., 1999; Murari et al., 2012; Carvalho \& Trevisan, 2015). Segundo Lunz et al. (2010), S. unidentatum é atraído, capturado e monitorado utilizando-se armadilhas de impacto iscadas com etanol. Sugere-se que o monitoramento com tais armadilhas seja realizado em portos e aeroportos, nos locais de armazenamento e trânsito de madeiras ou material lenhoso. Um modelo adequado a esse monitoramento é descrito por Carvalho \& Trevisan (2015). Essa medida, juntamente com as inspeções, auxilia na detecção precoce, permitindo que medidas sanitárias sejam tomadas de forma antecipada, no sentido de erradicar o inseto e sua consequente disseminação.

\section{Referência}

Agência de Defesa Agropecuária do Paraná. Disponível em: <http:// www.adapar.pr.gov.br>. Acesso em: 3 abr. 2017.

Brasil. Ministério da Agricultura, Pecuária e Abastecimento. Instrução Normativa ${ }^{\circ} 28$, de 24 agosto de 2016. Norma Técnica para a utilização da Permissão de Trânsito de Vegetais - PTV desta Instrução Normativa. Diário Oficial [da] República Federativa do Brasil, Brasília, DF, n. 164, p. 6-8, 25 ago. 2016a.

Brasil. Ministério da Agricultura, Pecuária e Abastecimento. Instrução Normativa $n^{\circ} .32$, de 23 de Setembro de 2015. Procedimentos de fiscalização e certificação fitossanitária de embalagens de madeira. Diário Oficial [da] República Federativa do Brasil, Brasília, DF, n. 1, p. 6, 24 set. $2015 \mathrm{a}$.

Brasil. Ministério da Agricultura, Pecuária e Abastecimento. Instrução Normativa $n^{\circ}$. 33, de 24 Agosto de 2016. Norma Técnica para a utilização do Certificado Fitossanitário de Origem - CFO e do Certificado Fitossanitário de Origem Consolidado - CFOC. Diário Oficial [da] República Federativa do Brasil, Brasília, DF, n. 164, p. 18-27, 25 ago. 2016 b.
Brasil. Ministério da Agricultura, Pecuária e Abastecimento. Instrução Normativa $\mathrm{n}^{\circ} .36$, de 10 novembro de 2006. Atualização dos procedimentos operacionais do Sistema de Vigilância Agropecuária. Diário Oficial [da] República Federativa do Brasil, Brasília, DF, n. 218, p. 3-32, 14 nov. 2006.

Brasil. Ministério da Agricultura, Pecuária e Abastecimento. Instrução Normativa $n^{\circ} .41$, de 01 de Julho de 2008. Altera os Anexos I e II da Instrução Normativa ${ }^{\circ}$. 52, de 20 de novembro de 2007. Diário Oficial [da] República Federativa do Brasil, Brasília, DF, n. 125 , p. 8, 02 jul. 2008.

Brasil. Ministério da Agricultura, Pecuária e Abastecimento. Instrução Normativa $n^{\circ}$. 59, de 18 de Dezembro de 2013. Altera o Anexo II da Instrução Normativa $n^{\circ}$. 41, de $1^{\circ}$ de julho de 2008. Diário Oficial [da] República Federativa do Brasil, Brasília, DF, n. 249, p. 4-5, 24 dez. 2013.

Brasil. Ministério das Relações Exteriores. Divisão de Inteligência Comercial. Como exportar: Indonésia. Brasília, DF: MRE, 2015b. $79 \mathrm{p}$.

Brasil. Normas internacionais para medidas fitossanitárias: regulamentação de material de embalagem de madeira no comércio internacional. Brasil, 2009. 15 p. Disponível em: <http:// www. martmadeiras.com.br/produtos/NIM15_\%20InteiroTeor_2009.pdf $>$. Acesso em: 18 out. 2017.

Cai tempo médio de liberação de contêineres no Porto de Santos. A Tribuna: Porto \& Mar, 28 abr. 2017. Disponível em: <http://www. atribuna.com.br/noticias/noticias-detalhe/porto $\% 26 \mathrm{mar} /$ cai-tempomedio-de-liberacao-de-conteineres-no-porto-de-santos $/$ ?cHash=9 e66d75d4e9349f881d71b05b864f649>. Acesso em: 15 out. 2017.

Carvalho, A. G. \& Trevisan, H. Novo modelo de armadilha para captura de Scolytinae e Platypodinae (Insecta, Coleoptera). Floresta e Ambiente, v. 22, n. 4, p. 575-578, 2015. DOI: 10.1590/21798087.105114.

Fariello, D. \& Ordoñez, R. Movimento no Porto do Rio cai três vezes mais que a média nacional. O Globo: Economia, 28 mar. 2017. Disponível em: $<$ https://oglobo.globo.com/economia/movimento-noporto-do-rio-cai-tres-vezes-mais-que-media-nacional-21115030>. Acesso em: 15 out. 2017.

Ferraz, F. C. et al. Eficiência de armadilhas etanólicas para levantamento de coleópteros do reflorestamento de Eucalyptus citriodora em Pinheiral, RJ. Floresta e Ambiente, v. 6, n. 1, p. 159-162, 1999.

Flechtmann, C. A. H. \& Gaspareto, C. L. A new trap for capturing Scolytidae (Coleoptera), based on primary attraction. Journal of Applied Entomology, v. 121, n. 1, p. 357-359, 1997. DOI: 10.1111/j.1439-0418.1997.tb01419.x.

Furniss, R. L. \& Carolin, V. M. Western forest insects. Washington, DC: USDA, 1977. 654 p. (Miscellaneous publication, 1339).

Lunz, A. M. et al. Monitoramento de Sinoxylon conigerum (Gerstäcker, 1885) (Coleoptera: Bostrichidae) em Madeira de Teca (Tectona grandis L. f.) no Estado do Pará. Belém, PA: Embrapa Amazônia Oriental, 2010. 7 p. (Embrapa Amazônia Oriental. Comunicado técnico, 224). 
Murari, A. B. et al. Modelo de armadilha etanólica de interceptação de voo para captura de escolitíneos (Curculionidae: Scolytinae). Pesquisa Florestal Brasileira, v. 32, n. 69, p. 115-117, 2012. DOI: 10.4336/2012.pfb.32.69.115.

Penteado, S. R. C. et al. (Ed.). Insetos florestais de importância quarentenária para o Brasil guia para seu reconhecimento. Colombo: Embrapa Florestas, 2010. 82 p.
Peres Filho, O. et al. First record of Sinoxylon conigerum Gerstäcker (Coleoptera: Bostrichidae) in Brazil. Neotropical Entomolology, v. 35, n. 5, p. 712-713, 2006. DOI: 10.1590/S1519566X2006000500023. 